\title{
An Atheist Perspective on Self-Esteem and Meaning Making While Under Death Awareness
}

\author{
${ }^{\mathrm{a}, \mathrm{b}}$ Thomas J. Coleman III, 'Kenan Sevinç, ${ }^{\mathrm{d}}$ Ralph W. Hood Jr., \& ${ }^{\mathrm{a} J o n a t h a n ~ J o n g ~}$ \\ a Brain, Belief, and Behaviour Research Laboratory; Coventry University, UK \\ ${ }^{\mathrm{b}}$ Department of Psychology, Grand Valley State University, USA \\ ${ }^{\mathrm{c}}$ Department of Psychology of Religion, Canakkale Onsekiz Mart University, TU \\ ${ }^{\mathrm{d}}$ Department of Psychology, The University of Tennessee at Chattanooga, USA
}

Citation: Coleman, T. J. III, Sevinç, K., Hood, R. W. Jr., \& Jong, J. (2019). An atheist perspective on self-esteem and meaning making while under death awareness. Secular Studies. 1(2). (in press)

Corresponding author: Thomas J. Coleman III, coleman@gvsu.edu

ORCID ID: Coleman, 0000-0002-3003-5090; Hood, 0000-0002-5165-6830 Jong, 0000-0002-

8039-9298 


\begin{abstract}
In accordance with Terror Management Theory research, secular beliefs can serve an important role for mitigating existential concerns by providing atheists with a method to attain personal meaning and bolster self-esteem. Although much research has suggested that religious beliefs are powerful defense mechanisms, these effects are limited or reveal more nuanced effects when attempting to explain atheists' (non)belief structures. The possibility of nonbelief that provides meaning in the "here and now" is reinforced by the importance placed on scientific discovery, education, and social activism by many atheists. Thus, these values and ideologies can, and do, allow for empirically testable claims within a Terror Management framework. Although religious individuals can and largely do use religion as a defense strategy against existential concerns, purely secular ideologies are more effective for atheists providing evidence for a hierarchical approach and individual differences within worldview defenses. Evidence for and implications of these arguments are discussed.
\end{abstract}

Keywords: Terror Management Theory; Atheism; Secular; Nonbelief; Implicit Belief; Nonreligion; IAT 
An Atheist Perspective on Self-Esteem and Meaning Making While Under Death Awareness

Over the past several decades, a continually growing body of research suggests that religion can provide a set of beliefs and customs that form an effective way to improve overall well-being and decrease anxiety (Arrowood, Pope and Harlow 2014; Lavric and Flere 2010; Rosmarin Krumlei and Andersson 2009). This understanding of the therapeutic benefits of religious adherence is not limited to daily stressors, however. A more recent body of research suggests that religious belief can provide an effective buffer for existential concerns (Vail et al. 2010). For theistic individuals, religious beliefs and adherence can serve as a buffer that lessens the terror associated with death and dying. These effects are robust and can singularly counteract adverse outcomes inherent in death awareness (Dechesne et al. 2003). This raises an interesting question for the increasing number of atheists and nonreligious individuals in today's society: If theistic beliefs are so efficacious in ameliorating the fear of death for believers, can the beliefs held by nonbelievers operate similarly, and what might these beliefs be? In the present article, we review selected Terror Management Theory (TMT) research on theist and atheist individuals and develop an alternative view for understanding and explaining worldview defense mechanisms in atheists, specifically when utilizing indirect or implicit measurement techniques, by arguing atheistic beliefs can serve as an effective way to boost self-esteem and attain meaning following death awareness.

Terror management theory suggests that when we are aware of our death, we are driven to boost our self-esteem within a cultural framework that allows us to attain personal meaning (Greenberg, Pyszczynski and Solomon 1986). TMT posits that by boosting self-esteem within a cultural context, we do not have to worry about the finality of death (the ultimate punishment), because living up to religious tenets or other beliefs integral to the culture in which we live can 
afford us literal salvation (in the case of most religions) or symbolic salvation (something that lives on beyond us) (Greenberg et al. 1986). Much of TMT is based on the works of Ernest Becker (1973) in which he argued that because humans are capable of complex thought, they are also capable of thinking about their purpose and meaning in life. Additionally, we can conceptualize our impending death. In order to contend with this realization, we have several worldview defense mechanisms that allow us to boost our self-esteem (Greenberg et al. 1986). Furthermore, following death awareness, humans are more confident that the world is purposeful (Davis, Juhl and Routledge 2011) suggesting that when faced with existential concerns, people must view the world as purposeful in order to attain personal meaning within their culture. Thus, by viewing the world as meaningful and purposeful, we can boost our self-esteem by living up to the belief systems and rules inherent within our culture. Within this need for self-esteem, we react negatively against those who do not uphold our personal worldviews because they threaten the validity of those beliefs (Schimel et al. 1999). Thus, TMT provides a way promote selfesteem by promoting the culture in which one lives.

\section{Current Research into Terror Management, Religion, and Atheism}

Research suggests that religious belief provides an effective way to contend with existential concerns (Becker 1973) and death anxiety (Jong and Halberstadt 2016; Jong, Halberstadt and Bluemke 2012; Vail et al. 2010). Not only does religion offer its followers with a set of tenets and rules to follow, but more importantly, it outlines a way to achieve a literal, immortal afterlife. By following the religious tenets and rules, followers can be "confident" that they will escape nonexistence and live forever, thus allowing them to defend against death anxiety (van den Bos et al. 2012). Additional research suggests that when followers are more devout to the primary teachings of the religion (e.g., belief in God and an afterlife), they 
experience less death anxiety and are more acceptant of death (cf. Jong and Halberstadt 2016). In addition to this literal afterlife, religion offers more symbolic immortality to contend with death anxiety. The various rules and tenets found in religion also provide followers a way to bolster self-esteem. Living up to one's religious belief systems by following its rules and customs allows the follower to be part of a larger group that supersedes any individual member (Vail et al. 2010). Additionally, believers can deny death by remembering times that they upheld their religious values. This provides comfort, according to TMT, because theists believe that a just God/gods would not allow someone promoting their religion to die.

Although this defense strategy can be quite beneficial for followers of a religion, a paradoxical outcome occurs for atheists. According to TMT, atheists should bolster their secular worldview when confronted with reminders of mortality (Greenberg et al. 1986; Jong et al. 2012). They should be more confident in doubting religious beliefs and that supernatural agents do not exist, in contrast, some research suggests that religious ideation becomes a more effective shield against death awareness for even atheists (Heflick and Goldenberg 2012, Jong et al. 2012; Vail et al. 2010). In a theoretical argument for the importance of religion as a worldview defense, Vail et al. (2010) argue that religious beliefs, unlike many secular beliefs, do not need to be based in logic, therefore, they do not need evidence in order to bolster them. Thus, without the need for evidence, it is nearly impossible to provide disconfirming evidence that could be used to challenge religious claims. Alternatively, many secular worldviews are based entirely in reality, and can therefore be challenged with contradictory evidence. This, in part, can explain much of the persistence of religious belief. Additionally, within a TMT framework, because religion cannot be challenged in a similar fashion as secular beliefs it provides a superb defense against mortality concerns by providing "irrefutable" evidence of immortality. 
Additionally, the tenets and rules found in religion allow anyone to boost their selfesteem if they choose to follow them. Consider the Christian tradition, "You shall love your neighbor as yourself” (Mark 12:31, English Standard Version). This Biblical argument for the "Golden Rule," however, can be followed by both the religious and nonreligious. According to Christianity, this, along with loving God, is the greatest commandment and supersedes all others. Thus, at least in principle, both atheists and theists can use this and other teachings as a way to boost self-esteem and shield against mortality concerns. Conversely, this tenet is widely known and often embraced regardless of the religious connotation. However, TMT research suggests atheists will adopt an implicit belief in supernatural agents (e.g., God, angels, demons) when confronted with mortality concerns. According to Jong et al. (2012), although atheists explicitly strengthened their nonbelief in supernatural agents following mortality salience, implicitly they were more likely to associate supernatural agents with real beings. Using a speeded categorization task and an Implicit Associates Test (IAT: Greenwald, McGhee and Schwartz 1998) with supernatural agents as the target, atheists were faster to respond that these supernatural agents were real following a mortality prime.

One explanation for the findings of the study by Jong et al. (2012) is that, at least momentarily, their sample of atheists became "implicitly theistic." This is possible, because although atheists reject the existence of supernatural agents that control the fate of all people and the world, they contain the same cognitive mechanisms as theists that generate these agents as by-products of ordinary human thinking (Coleman, Hood and Shook 2015; McCauley 2011). One mechanism that may become activated when primed with mortality salience is the hypersensitive agency detection device (HADD). According to Barrett (2012), HADD is tuned to become more active under conditions of survival (i.e., life and death situations). From this 
evolutionary perspective, the costs of detecting an agent who really isn't there are minimal, a bruised ego at best. However, failing to detect an agent who is really there could come with a high cost, your life.

This evolutionary account may explain much of Jong et al.'s (2012) findings that atheists implicitly endorsed supernatural thinking following death awareness. Considering a literal immortality and TMT, the HADD can further explain much of this research. Jong et al.'s (2012) version of the IAT used supernatural places such as Heaven. From a Biblical perspective, Heaven is an eternal place in which believers will live forevermore. By temporarily endorsing this type of religious thinking, both atheists and theists alike can subconsciously entertain a "literal" afterlife. Granted, with these thoughts of an afterlife, an atheist can also think about the antithesis of a Heavenly afterlife of which nonbelievers may be destined to inhabit. Although Hell is described as a terrible place of eternal torment, an existence in Hell is still an immortal existence. From the TMT perspective developed here, although it is a terrible existence, it still provides a buffer against the anxiety associated with nonexistence because it provides an immortal existence. Although these thoughts about an afterlife can be discomforting due to the descriptions of these realms, from a shear existential perspective they provide a defense against nonexistence that cannot be disproved in which they can only buffer existential anxiety. Thus, with these implicit associations between death and "real" supernatural agents and places, Jong et al. (2012) demonstrate that although atheism can provide a viable explicit worldview defense, religion may provide a stronger implicit defense against existential terror ${ }^{1}$.

\footnotetext{
${ }^{1}$ We would like to distinguish the difference between implicit belief and temporary supernatural thinking. Although Jong et al. (2012) suggested that atheists were more likely to implicitly respond in a manner indicating supernatural agents are real following death awareness, this should not be taken as evidence that death awareness caused religious conversion. Instead, the temptation to endorse temporary religious thoughts may be evolutionarily adaptive because of the inability to disprove a literal afterlife. We would like to thank Dr. Ken Vail (K. Vail, personal communication, April 2015) for his input on this phenomenon.
} 
Additional research suggests that evidence of an afterlife is also an effective shield against death awareness for theists and atheists alike. Heflick and Goldenberg (2012) argue that when symbolic and literal immortality are in conflict (such as with an atheist who hears evidence of an afterlife) the literal immortality will provide a more effective shield against death awareness and therefore reduce the need for symbolic immortality. In a comparison of atheists, agnostics, and theists, Heflick and Goldenberg gave each group a "credible" essay that gave scientific evidence for the existence of an afterlife followed by the typical death essay prime. Following this, participants read an essay that criticized or promoted the United States (Greenberg et al. 1990) to assess worldview defense manifestation. A separate group of Atheists, Agnostics, and Theists were given these same measures, but were given "scientific evidence" that an afterlife could not exist. The researchers ${ }^{2}$ suggested that following the afterlife affirming evidence, all three groups demonstrated decreased worldview defense. Conversely, without the afterlife disconfirming evidence, each group showed the typical worldview defense boost. These results suggest that afterlife beliefs can and are bolstered in order to shield against death anxiety in atheists and theists alike.

\section{An Alternative View to Current TMT and Atheism Research}

Although much of the research on TMT and atheism (admittedly this is a very small, but growing, field) argue that religion is an effective buffer of death anxiety (Heflick and Goldenberg 2012; Jong et al. 2012; Vail et al. 2010), we argue that much of these results are slightly misleading (unintentionally so) and may actually be illustrating a more nuanced effect.

\footnotetext{
${ }^{2}$ The included emphasis on researchers is due to a post hoc finding that the data was misreported. Although we discuss this misreporting in detail further on, it is important to discuss the current thinking with the field of TMT and religion and how this research influenced much of the importance placed on religious worldviews.
} 
In part, this is symptomatic of a more general problem across the social scientific study of nonreligion in which researchers tend to 1) conceptualize nonreligion as the mere opposite of religion (Coleman, Hood and Streib 2018), or 2) view all humans as implicitly theistic (cf. Coleman and Messick in press). For example, much of the evidence that atheists use theistic beliefs as a defense mechanism argues that they hold these beliefs implicitly. However, the true definition of a belief has been one of the core questions behind philosophy and science for hundreds of years, with no definitive answer (Lanman 2008). Moreover, what constitutes a "religious belief" is an even more problematic question, which has only begun to receive attention from humanists and scientists (see, Angel et al. 2017; Coleman, Jong and van Mulukom 2018). There is no empirical test or experiment that can demonstrate a holistic understanding of a belief, however depending on what a belief is (or isn't) strongly influences how empirical research is written up, discussed, and shared with the public. Importantly, these results have wide ranging social impacts, and government policy decisions are often informed by scientific research (Hanft 1981) (e.g., Does a response on an implicit association test for racism demonstrate what someone "really believes," despite that they may say they believe opposite? [Payne 2001] If so, can these people be trusted?).

In the fields of psychology of religion (POR) and cognitive science of religion (CSR, what it means to have a belief has been a neglected topic (Jong 2013), despite its obvious centrality to religion. One reason for this may be that the long history of POR has been primarily concerned only with reportable beliefs, that is, beliefs as they can be expressed by verbal utterance. However, CSR is a much more recent endeavor focusing on the cognitive processes and mental representations that may underlie religious belief and this has complicated what it 
means to have belief (cf. Lanman 2013). Specifically, this has been complicated in the context of TMT by Jong et al.’s (2012) arguments for "implicit religious belief.”

One operationalization of "belief” in CSR, as suggested by Barrett and Lanman (2008, 124 , emphasis ours), is “...the state of a cognitive system holding information (not necessarily in propositional or explicit form) as true in the generation of further thought and behavior". This "minimal, functional definition" (Lanman 2008, 54) is just ambiguous enough to entail that any and all information that can be held in the brain may candidate for a "belief," despite being "believed in." If a belief is defined in this way, as the totality of information held in the brain, then what we may take to mean as a belief in any folk sense of the term is gone from our understanding of belief and it bears little relationship to the latter, as we now have a potentially innumerable number of beliefs that are not believed in, from the abhorrent and cruel to the obscure and meaningless.

Almost all theories of cognitive science (or other disciplines likewise) make appeal to the conscious and unconscious processing of representations. Processing meaning that in which, representations can be used by a system to run functions both with and without their contents being explicitly acknowledged or assented to (Von Eckardt 2012) and in this sense, priming techniques may cue up certain schemata or associations that may not inform one's attitudes or reflect "beliefs" (Fazio 2007; Fazio and Olson 2003; Olson, Fazio and Han 2009). This primarily implicates any "belief” derived from the IAT. It may be premature or even incorrect to assume that the IAT is measuring an "implicit belief." Jong et al.'s (2012) study builds on Uhlmann, Poehlman, and Bargh's (2008) suggestion that there may be such a thing as "implicit theism," in which religiosity is the default cognitive setting for humans as it stems from system one cognition (cf. Jong 2018). Interestingly, both Lanman (2013) and Coleman (2013) have 
suggested that it is entirely plausible that such a thing as "implicit atheism," exists, despite explicit claims to theistic belief. But nonetheless, no human runs on purely system one cognition and there is no "system one religion." "Religious intuitions" (if they can be called such) are always handled by higher, more reflective system two, levels of cognition and recent appeals to conceptualize religiosity as necessitating both types of cognition illustrate this finding (Baumard and Boyer 2013; Morgan 2014; Jong 2014; Van Leeuwen 2014).

Importantly, there is no such thing as "religious cognition," only cognitions deemed religious (Taves 2009). In other words, religion is in the eye of the beholder. Both theists and atheists share the same cognitive processes and mechanisms (Banerjee and Bloom 2013; Coleman and Hood 2015; Geertz 2013; Geertz and Markusson 2010; Gervais et al. 2011; McCauley 2011; Taves 2013, 2015). Therefore, how does one go from warranting a "belief," as measured by the IAT, which "assesses strengths of associations between concepts [stored in memory] by observing response latencies in computer-administered categorization tasks" (Greenwald et al. 2009)? The IAT and other implicit measures are clearly measuring something, but whether or not this is a belief is first and foremost a theoretical decision.

It is important to consider that the IAT measures exactly what its name implies, implicit associations. Representations are stored in memory and are linked to other representations/concepts. For example, broom is linked to floor. If an individual is primed with the concept CLEANING it will cue up broom and vice versa. Much more is understood about the linkage between these concrete concepts as opposed to abstract concepts (McRae and Jones 2013). Regarding concreteness, the object broom exists in the world - we can point to a broom and also observe someone cleaning or use the broom to clean the floor ourselves. However, for abstract concepts (e.g., HEAVEN; which is one of the concepts used in the Jong et al. [2012] 
IAT study) this process is much more problematic. We cannot point to an example of Heaven (sans a vacation in Fiji), much less observe someone going there. What is the meaning of HEAVEN?

In this sense, the linkages between abstract concepts in memory, how they are simulated and computed or their actual content, are in dispute - we just don't know yet (McRae and Jones 2013). Furthermore, the content of a concept matters, particularly for IATs using abstract religious concepts. For example, a common expression used by both theists and atheists to denote a physical place or action, which may feel enjoyable, pleasant, sublime, incredible etc., is, "this place feels like heaven!" In this sense, the meaning of HEAVEN is grounded in virtue of having very tangible and natural content. Nonetheless, if the mental content of HEAVEN is a vacation in Fiji, then most people would enjoy visiting this place and cueing up this simulation (Barsalou 1999; Pecher 2013). Furthermore, this might even give the atheist grounds to "implicitly believe" in it, however this heaven does not have any theological meaning. Even among theists it would be naive to presume at the level of implicit online cognition that abstract religious concepts have a unified or even theological content. Based on his reading of an earlier draft of this article, Jonathan Jong (2018, pp 296-297) recognizes this as a potential problem and suggests that "abstract concepts have indeterminate meaning and are susceptible to massive inter-individual differences," but we all agree these problems are scientifically tractable. Further research is desperately needed to investigate these issues, but the first author of the current article (Coleman) argues that research on anthropomorphism in god concepts can serve as a preliminary testcase.

For example, despite that theists explicitly represent God in the theologically correct sense as being omniscient and omnipresent, when under speeded response God is strongly 
anthropomorphized (McCauley 2011). He has the same representational content as an average human, being limited by time, space, and even knowledge (for review, see Heiphetz et al. 2015). In addition to "Heaven," which we discussed above, Jong et al. (2012) also used "God" in their IAT measure of "implicit belief." What is the content or meaning of the abstract concept GOD at the implicit level? If we take the extensive research on anthropomorphism in god concepts as evidence, GOD appears to be "just another person." The answer may not be a theological one, however it might be starring us in the face.

But in steeping back from conceptual issues involved in cognition, the IAT measures “automaticity" and not necessarily "implicitness" (Olson et al. 2009, 153). To borrow examples drawn from Olson, Fazio, and Han (2009), IAT studies have demonstrated that smokers have negative attitudes toward smoking at the implicit level (e.g., Swanson, Rudman and Greenwald 2001) and that heavy drinkers might actually harbor negative views about alcohol (e.g., Wiers et al. 2005). Also, it would appear that African Americans do not prefer other African Americans to Caucasians implicitly and hence stand as a curious violation of universal in-group favoritism (Fazio and Olson 2003; Olson et al. 2009). Certainly, this observation is perplexing, however, the answer may lay in what Olson, Fazio, and Han $(2009,152)$ term as "extrapersonal associations." In sum, not every representation stored in memory may inform one's attitudes or be endorsed (Coleman, Hood and Shook 2015). That is, knowledge of an association between two concepts and not necessarily belief in this association is also measured by the IAT. Because of prevalent stereotypes that drinking, and smoking are bad, and culturally disliked, these associations can become connected in memory and are then available for activation at an implicit level. Furthermore, because racism is rampant and both African Americans and Caucasians are exposed to negative stereotypes of African Americans, these associations may explain the 
discordancy present in IATs that suggest Africans Americans do not implicitly prefer other African Americans to Caucasians. Perhaps, however, these paradoxical trends can be reversed when the IAT is "personalized?"

In Jong et al., their study used an IAT that involved parsing supernatural entities into the categories "real" versus "imaginary" (2012, 985-986) however, these types of judgments are precisely the kind vulnerable to extra personal associations. For example, Olson, Fazio, and Han (2009) detail the problems with this value distinction when they suggest categories such as pleasant or unpleasant and good or bad (typical IAT categories used for studies on implicit attitudes) may be to blame for the curious IAT responses discussed previously. The question becomes, liked or disliked for whom? The individual or the rest of one's culture? When IATs are "personalized," in that the categories are changed to "I like" or "I dislike," for example, African Americans demonstrate implicitly preferring other African Americans and people who explicitly enjoy drinking alcohol and smoking tobacco can be found to harbor implicit attitudes that reflect this (Olson et al. 2009).

Regarding Jong's study, we might ask, for whom are these supernatural entities real or imagined for? Again, why would an atheist respond in a manner that associated the MS prime with supernatural belief? Perhaps, simply in virtue of extrapersonal associations relative to the culturally available value judgments of religion and supernatural concepts as "real" and the connection between death and religiosity. In essence, when the atheist responds in a particular fashion on an IAT, rather than indicating "implicit belief," the IAT may simply be measuring the residual--bleed over--explicit belief of the rest of society. Similar distinctions have been proposed by Gervais et al. (2011), in chastising CSR researchers for focusing solely on how representations and concepts are transmitted culturally and not how these concepts come to be 
"believed in." It is one thing to be able to hold a representation in mind and quite another to believe in this representation (e.g., I can think of a pink unicorn, but I do not believe in this imaginative creature). Now, given that, to some degree, the notion of extrapersonal associations could be considered "fuzzy" due to its appeal to "culture" (cf. Olson et al. 2009), we must consider an alternative source. Namely, having a parent, spouse, valued friend, social peers or other prestigious individuals that maintains and truly believes in these associations is another avenue for representations to be linked in memory (Cosmides and Tooby 2000; Henrich 2009). For example, if someone has spent years of their life viewing their mother and father attend church, reading the Bible, saying prayers before meals, reciting the Rosary, even remarking "at least I know the Lord loves me and I will go to Heaven when I die," then the fervency of faith mitigating existential concerns could become subconsciously linked in even the mind of an atheist.

While IATs have a good record of measuring implicit attitudes, in that these implicit attitudes can give way to behavior or explicit belief, IATs measure much more than only the possibility that an individual holds an implicit attitude. Furthermore, explicit ecological verification or refutation of an implicit attitude or a misleading belief, is much easier for the case of racism or the fondness for tobacco and alcohol than belief in God. On one hand, you are better able to confirm implicit racism by observing your co-worker refuse service to African Americans but not Caucasians, or to refute their claim of disliking tobacco and alcohol by catching them sneaking a drink and a smoke on a work break. On the other hand, however, it is not clear how you might catch or observe an atheist believing in God despite the explicit claim that they do not.

Extrapersonal associations can and do also effect IAT responses. Further, depending on what the content of a specific representation is that comes to mind (cf. Barsalou 1999; McRae 
and Jones 2013), an atheist responding faster at placing "Heaven" in the "imaginary" category after mortality salience (indicating “implicitness") may not be reflecting a discordant belief. Perhaps rather than measuring an "implicit belief," the IAT used in Jong's study is simply measuring deeply ingrained cultural stereotypes, meta-representations not believed in (Fazio and Olson 2003; Olson, Fazio and Han 2009). That is, since the stereotype exists (it's truth or falsity is not relevant here) that religion is one domain that can help individuals mitigate existential concerns; it is reasonable to assume that such stereotypes are activated in the IAT response, however do not qualify as "implicit attitudes." We suspect that Jong et al. $(2012,988)$ might even agree with us, as they conclude:

...these inconsistencies in our view represent the flexibility of multi-level representation, which permits individuals to gain the maximal psychological benefits from both the content of their beliefs and the worldviews in which they are situated.

Methodological rigor and data interpretation are critical. For example, when confidence in one's world-view is taken into account, rather than mere "belief" itself, there is a curvilinear relationship for mental well-being between atheists and theists (Galen and Kloet 2011; Galen 2015). Typically, studies have collapsed atheists into the non or low-religious category or conflate the self-identification of non-religious with atheist. This has generated false assumptions about the psychology of atheists in research on Prosociality (for review, see Galen 2012) and health and well-being (Coleman, Hood and Shook 2015; Galen 2015; Speed, Coleman, Galen and Hwang submitted). Elsewhere, research on mentalizing ability suffers from similar data misinterpretations (e.g., De Cruz 2016; mis-reading Norenzayan, Gervais and Trzesniewski 2012). For similar reasons, below we further suggest rejecting the intimation put forward in Jong et al. (2012) that "implicit belief" was increased in atheists. While their study is an important one, it may not be yielding insight into "implicit belief." 
A closer look at the methods section of Jong et al. (2012) reveals some strong methodological limitations to any conclusion that "implicit belief" may have been bolstered. For example, only in study 1 were there ever any self-classified atheists (p. 985). Furthermore, they were then collapsed into a single category (i.e., as "non-religious"), which, rather than being filled solely with self-identified atheists, contained self-identified "non-religious" (87.23\%), "agnostics" (2.13\%), and then "atheists" (10.64\%). Perhaps unsurprisingly, when parsed out, the religious participants scored significantly higher than the self-identified non-religious, who in turned scored significantly higher than the self-identified atheists on a self-report measure of supernatural belief. For the analysis using the MS prime, however, only the religious and nonreligious groups were compared and Jong et al. (2012) did find that typical worldview defense mechanisms were bolstered. In contrast to study 1 , the researcher's sample for study 2 did not consist of any atheists, only 95\% "non-religious" and 5\% "agnostics" (p. 986). Furthermore, in study 3 no religious self-identification was used, only the supernatural belief scale and an IAT measure of supernatural belief using the categories of "real" and imaginary." As discussed previously, these types of IAT categories are particularly vulnerable to extrapersonal associations (cf. Olson et al. 2009). Additionally, in study 3 the participants were instructed to respond as "quickly and accurately as possible" (p. 986), thus how fast or slow does one have to respond to be considered an atheist? While the IAT categorization response times were highly correlated with the supernatural belief measure (p. 987), this fails to indicate whether there were actually any atheists in study 3 .

In sum, it is very plausible that the sample from study 3 was much similar to study 2 , in which there were no atheists, or perhaps even study 1 , in which there were only $10.64 \%$ atheists. In taking into account the marginal number of atheists in the Jong et al. (2012) sample, combined 
with the fact they verified that the largest group, the self-identified non-religious (87.23\%), scored significantly lower on supernatural belief than the religious, it is plausible that the effects of studies 2 and 3 were carried out entirely by non-religious participants - not atheists. Thus, any conclusion that atheists wavered from their disbelief is unsupported by the data.

Although we have argued for a different interpretation, Jong et al. did provide evidence of some phenomenon occurring, however, other TMT research further questions their results. Heflick and Goldenberg (2012) reported evidence suggesting that atheists use religion to shield against existential anxiety, but a closer look at the means reported in the article yield some evidence of mis-reporting. Vail, Soenke, Waggoner, and Mavropoulou (2019) obtained access to the data, and their additional analyses revealed that evidence of an afterlife only affected atheists in the control condition $(t[24]=2.50, p=.02)$ and had no effect in the mortality salience condition $(t[20]=-90, p=.38)$. Additionally, Vail et al. (2019) conducted two studies which corroborates this finding. In study one, as expected atheists utilized secular worldview defense in both the afterlife confirmed and disconfirmed condition. In study two, atheists again utilized secular worldview defense in the afterlife confirmed condition, but when presented with a condition confirming a naturalistic immortality (medical indefinite life extension), the need for worldview defense was eliminated. Moreover, an earlier study by Vail, Arndt, and Abdollahi (2012) found that although a death prime increased religiosity, belief in God, and a higher power among Christians, atheists were unaffected. Similar to study one in Jong et al. (2012), these results (and lack of results in the case of Heflick and Goldenberg [2012]) suggest that explicit religiosity does not provide a viable shield against death awareness for atheists, which is concordant with their beliefs. Alternatively, these results may provide evidence that atheists use a different type of worldview defense mechanisms for meaning making and to boost self-esteem. 
In other TMT studies, this research further suggests a distinction in using religion as a defense mechanism even among those of faith. For example, Arrowood, Coleman, Swanson, Hood, and Cox (2018) found that individuals who were high in quest orientated religiosity reported lower self-esteem following morality salience. This suggests that types of religiosity that resist holding strong religious conviction may be less effective at buffering against mortality salience. Similarly, Jonas and Fischer (2006) found a significant distinction between those who score high and low on measures on intrinsic religiosity. Primarily, intrinsically religious people use their religion to combat mortality salience instead of the typical worldview defenses. Conversely, those who were not intrinsically oriented reacted by bolstering typical worldview defenses (i.e. reacting favorably toward those who uphold cultural values). Considering Allport's (1966) initial distinction between intrinsic and extrinsic religiosity, those who are intrinsically oriented are internalizing these beliefs, perhaps explaining why they bolstered their beliefs following death awareness. Thus, even among the self-identified religious, worldview defense mechanisms show variation. Regardless of the explanation, these results reveal an important argument considering atheism and TMT. As intrinsic religiosity decreases or quest orientation increases, so does the likelihood of effective utilization of religion as a defense mechanism. Atheists, who by definition are not religious, should not utilize religion as a defense mechanism against death awareness and much of TMT suggests this (e.g., Vail et al. 2019). Because atheists do not use religion, it is important to consider what atheists use instead as a defense mechanism.

\section{Secular Defense Mechanisms}

A growing body of research into TMT has revealed a substantial number of possible secular worldview defense mechanisms that can allow one to boost self-esteem when under 
death awareness (Arrowood and Pope 2014). Arndt, Greenberg, and Cook (2004) suggest that nationalism and patriotism are effective as shields due to symbolic immortality and group belonging. Further, children can provide meaning and value (Baumeister 1991) and allow parents to pass on belief structures integral to TMT. Further, Fritsche et al. (2007) demonstrate that following death awareness, the desire for children can be greatly bolstered. Although each of these worldview defenses are secular by nature, we argue that atheists can adopt additional, unique secular defenses due to methods that they use to attain meaning and promote self-esteem. Moreover, because atheists are more likely than theists to report that meaning in life is something that each person must construct for themselves, secular sources of meaning may demonstrate substantial variation in type. Nevertheless, by using the Building-Block Approach inspired by Taves $(2009,2013)$ and outlined by Coleman and Arrowood (2015), it is possible to elucidate an "Atheist's Salvation" that can be used to bolster self-esteem. Primarily, this "Salvation" is contained to the "here" and "now" of human existence. They argue that if the religious frameworks are removed from the salvation process, one would be left with a belief component and an action component that can be used to provide meaning. Just as a religious salvation can allow believers to go to a better place (i.e. Heaven), so too does a secular salvation in which atheists also go to a better place (a better physical world).

Religious belief in a higher power is by definition accompanied by actions that profess this belief (e.g., church and mosque attendance, tithing or giving Zagat; "sign following believers" in the Southern U.S. handle serpents, Hood and Williamson 2008). From this building-block approach, an atheist's belief in a better world here and now is also accompanied by actions that attempt to create that better world. Taken from interviews where atheists in America were asked about important concerns and causes, Coleman and Arrowood (2015) argue 
that atheists can achieve salvation by making the world a better place that will live on past any individual person. Their participants discussed themes such as human progress and flourishing, social activism, science, and education / critical thinking. More recently, these themes were identified in the top ten most frequently mentioned responses in a study that asked atheists in ten countries to report what deeply meaningful worldviews and beliefs they held if they did not believe in God (van Mulukom et al. submitted). Broadly speaking, these atheists were interested in taking action, creating change, moreover, progress. From a TMT perspective, social change that lives on past the originator can provide symbolic immortality. By instigating social change, atheists can achieve a legacy that allows their ideas to live on despite a physical death. It is through this change that atheists can escape the threat of nonexistence (for a proof of concept in secular individuals, see Rutjens et al. 2014). Thus, what begins with immediate change can prosper into continued and long-lasting change, or symbolic immortality. A review of the TMT literature fails to find any research in which atheists were allowed to bolster social activism, societal change, or other constructs that are important to them. This causes the typical worldview defenses to manifest in order to contend with death anxiety (see Greenberg et al. 1994 for an example of typical worldview defense manifestation). By bolstering causes and changes, however, atheists should be able to successfully contend with death anxiety without evoking traditional, laboratory worldview defenses.

Within this desire for social change, atheists can and do attain meaning by participating and promoting education and science. Although Vail et al. (2010) argue that religious beliefs are stronger at alleviating death anxiety because they are not grounded in logic, it is entirely for this reason that secular beliefs are strengthened (also, see Van Leeuwen 2014 for arguments suggesting religious credence is not factual belief). Coleman and Arrowood (2015) argue that 
atheists are especially driven to promote social change and understand the world using science and logic (see also van Mulukom et al. submitted). Thus, an atheist should not endorse a religious worldview defense because these defenses are not logical or even defendable within a natural context. Conversely, a secular belief that can be challenged by the tools of science are integral to atheists' defenses against death awareness. Although this may seem counterintuitive to TMT in that we react negatively against threats to our belief structures (Schimel et al. 1999), this overarching belief in the importance of science should supersede belief in any individual concept.

A hierarchical view of defense mechanisms following death awareness is not a novel proposition within TMT. For example, Greenberg, Simon, Pyszczynski, Solomon, and Chatel (1992) found that following death awareness, although conservatives reacted negatively against liberals, liberals were much more accepting of conservatives. Initially, this finding would appear inconsistent with TMT, however, a much more nuanced pattern appears. By being more accepting of conservatives, they argue that liberals are simply endorsing an integral aspect of being liberal. This suggests that certain beliefs supersede others in order to shield against death awareness. Thus, we argue that by bolstering belief in science, even when contradicting other beliefs, atheists are utilizing a more meaningful way to boost self-esteem. Perhaps, this explains much of the lack of evidence in Heflick and Goldenberg's (2012) attempt to use "scientific evidence" to influence afterlife beliefs following death awareness. Both the afterlife confirming, and disconfirming evidence would have allowed atheists to bolster their belief in the power of science, which eliminated a true comparison group. Just as unquestioned belief in God is an integral part of a Christian's salvation and personal identity, questioned belief in science is an 
integral part of an atheist's salvation and personal identity. Thus, by bolstering science and their belief in science, atheists are promoting self-esteem and mitigating death anxiety.

These arguments for the importance of science and activism to make the world a better place gains considerable support in light of recent research, which suggests a more nuanced understanding of atheism being characterized as different "types." For example, Silver, Coleman, Hood, and Holcombe (2014) have provided empirical support for the existence of at least six different categories of atheism. In conjuncture with the narratives reported by Coleman and Arrowood (2015), Silver et al. (2014) identified six types of nonbelief: Intellectual Atheist/Agnostic, Activist Atheist/Agnostic, Seeker-Agnostic, Anti-theist, Non-theist, and Ritual Atheist/Agnostic. A closer examination of the types reveals that five of the six are deeply concerned with intellectual pursuits and activism, even if these pursuits are simply to try to understand the beliefs of others, as in the case of the Ritual Atheist/Agnostic. Of the remaining type, the Non-theist holds a rather apathetic view, which might not be as concerned with these pursuits: however, this type is much less common in comparison to the Intellectual Atheist/Agnostic (the most common and most intellectually driven). Additionally, this focus on intellectual pursuits as pivotal for atheists has been supported by other scholars (e.g., BeitHallahmi 2015; Caldwell-Harris 2012; van Mulukom et al. submitted), and analytic thinking is consistently related to nonbelief (Pennycook et al. 2013; Pennycook et al. 2016; Stagnaro et al. 2019; but see, Gervais et al. 2018 ),predicts endorsement of evolution (Gervais 2015). Thus, Silver and colleagues (2014) identification of belief in science and activism as a crucial component of most atheists' belief structures is justified. Furthermore, in consideration of Coleman, Silver, and Hood (2016), beliefs that are devoid of any religious or spiritual framework (such as science) can be integral to achieving meaning for an atheist. 
Within this paradigm, Farias, Newheiser, Kahane, and de Toledo (2013) found that following instances of stress and existential concern, belief in science can be bolstered. More importantly, their samples were primarily secular which largely fits within our argument for unique defense mechanisms among atheists. However, as discussed above regarding the study by Jong et al. (2012) conflating self-identified atheists with the non-religious can be problematic. But nonetheless, when it is imperative that one accepts science and uses it to attain meaning, these effects are also pronounced. For example, following death awareness, people are more likely to embrace evolutionary theory following arguments that this existence is meaningful and are more skeptical of intelligent design theory (IDT; Tracy, Hart and Martens 2011). An atheist who by definition should reject IDT and should endorse evolutionary theory, should react more harshly against IDT. Our argument for scientific meaning making becomes even stronger when considering that IDT should provide a way to view personal existence as meaningful and that an analytic cognitive style predicts increased belief in evolution (Gervais 2015). Considering Davis et al.'s (2011) argument that humans are more driven to view the world as meaningful following death awareness, this provides increasing evidence that science can be used to attain meaning. Tracy et al. (2011) argue that even without explicit reminders that evolution can be meaningful, certain groups (natural science students in study 5 of their study) immediately endorse evolutionary theory. Additionally, careers in the natural sciences are overwhelmingly represented by atheists (Beit-Hallahmi 2015). However, within the argument by Tracy et al. (2011), atheists should also endorse evolutionary theory without any additional evidence because of the importance they place on science. Naturalism can provide meaning for an atheist because it is an imperative aspect of their personal worldviews.

\section{Conclusion}


Much of the TMT research suggests the importance of religious belief following death awareness (e.g., Vail et al. 2010). However, our critique of the only study published to date (Jong et al. 2012) suggesting that atheists may boost "implicit belief" following MS calls into direct question the empirical reach of these findings. Furthermore, we have argued that among atheists, secular beliefs are more powerful at combating existential concerns. Nonetheless, of concern is the limited supply of empirical studies attempting to address these primarily secular worldview defenses. Ultimately, belief in science and social activism are successful mechanisms for achieving personal meaning for atheists because of the importance placed on "the here and now" (Coleman and Arrowood 2015). These mechanisms warrant further study within the scientific community. Thus, although religious individuals attain meaning by salvation delivered from a higher power, atheists use more non-belief, specific defense mechanisms to attain personal meaning when faced with existential concerns. Thus, in consideration of the mantra put forth by the draftees of the second Humanist Manifesto (Kurtz and Wilson 1973), it becomes apparent to the atheist that "no deity will save us; we must save ourselves."

\section{Acknowledgements:}

This research was graciously supported by an American Psychological Association Division 36 Society for the Psychology of Religion and Spirituality 2017 Research Seed Grant awarded to Thomas J. Coleman III. 


\section{References}

Allport, Gordon Willard. 1966. "The Religious Context of Prejudice." Journal for the Scientific Study of Religion 5(3): 447. doi:10.2307/1384172.

Angel, Hans-Ferdinand, Lluis Oviedo, Raymond F. Paloutzian, Anne L. C. Runehov, and Rüdiger J. Seitz. 2017. Processes of Believing: The Acquisition, Maintenance, and Change in Creditions. Cham: Springer International Publishing.

Arndt, Jamie, Jeff Greenberg, and Alison Cook. 2002. "Mortality Salience and the Spreading Activation of Worldview-Relevant Constructs: Exploring the Cognitive Architecture of Terror Management." Journal of Experimental Psychology: General 131(3): 307-324. doi:10.1037//0096-3445.131.3.307.

Arrowood, Robert B., and Brian J. Pope. 2014. "Terror Management Theory: A Theoretical Perspective on Origination, Maintenance, and Research." Modern Psychological Studies 20(1): 87-96.

Arrowood, Robert B., Brian J. Pope, and Tom Harlow. 2014. "The Relationship of Religiosity to Psychopathology" The Predictive Ability of Religious Orientation for Stress and Depression in College Undergraduates." Modern Psychological Studies 19:2, (2014): 3746.

Arrowood, Robert B., Thomas J. Coleman III, Sally B. Swanson, Ralph W. Hood, and Cathy R. Cox. 2018. "Death, Quest, and Self-Esteem: Re-Examining the Role of Self-Esteem and Religion Following Mortality Salience." Religion, Brain \& Behavior 8(1): 69-76. doi:10.1080/2153599x.2016.1238843.

Banerjee, Konika, and Paul Bloom. 2013. "Would Tarzan Believe In God? Conditions for the Emergence of Religious Belief." Trends in Cognitive Sciences 17(1): 7-8. doi:10.1016/j.tics.2012.11.005.

Barrett, Justin L., and Jonathan A. Lanman. 2008. "The Science of Religious Beliefs." Religion 38(2): 109-124. doi:10.1016/j.religion.2008.01.007.

Barsalou, Lawrence W. 1999. "Perceptual Symbol Systems." Behavioral and Brain Sciences 22(04). doi:10.1017/s0140525x99002149.

Baumard, Nicolas, and Pascal Boyer. 2013. "Religious Beliefs as Reflective Elaborations on Intuitions: A Modified Dual-Process Model". Current Directions in Psychological Science 22(4): 295-300. doi:10.1177/0963721413478610.

Baumeister, Roy F. 1991. Meanings of Life. New York: Guilford Press.

Becker, Ernest. 1973. The Denial of Death. New York, NY: Free Press. 
Beit-Hallahmi, Benjamin. 2015. Psychological Perspectives on Religion and Religiosity. East Sussex: Routledge.

Caldwell-Harris, Catherine L. 2012. "Understanding Atheism/Non-Belief as an Expected Individual-Differences Variable." Religion, Brain \& Behavior 2(1): 4-23. doi:10.1080/2153599x.2012.668395.

Coleman III, Thomas J. 2013. Implicit Frameworks: The Tyrannical Hegemonic Discourse._The Nonreligion \& Secularity Research Network Official Blog, Methods and Methodologies. http://blog.nsrn.net/2013/11/01/implicit-frameworks-the-tyrannical-hegemonic-discourse/ (accessed July 24, 2019)

Coleman III, Thomas J., and Kyle J. Messick. in press. "Keeping the Secular Deck Intact". Implicit Religion [Peer Commentary on the Paper "Is Secularism a World Religion?" By D. Schaefer and C. Cotter].

Coleman III, Thomas J., and Robert B. Arrowood. 2015. "Only We Can Save Ourselves: An Atheist's 'Salvation'." In Alternative Salvations: Engaging the Sacred and the Secular, ed. Hannah Bacon, Wendy Dossett, and Steve Knowles (London, England: Bloomsbury Academic): pp. 11-20. doi: 10.5040/9781474220101.0007

Coleman III, Thomas J., Jonathan Jong, and Valerie van Mulukom. 2018. "Introduction to the Special Issue: What Are Religious Beliefs?" Contemporary Pragmatism 15(3): 279-283. doi:10.1163/18758185-01503001.

Coleman III, Thomas J., Ralph W. Hood Jr., and John R. Shook. 2015. "An Introduction to Atheism, Secularity, and Science." Science, Religion and Culture 2(3): 1-14. doi:10.17582/journal.src/2015/2.3.1.14.

Coleman III, Thomas J., Ralph W. Hood Jr., and Heinz Streib. 2018. "An Introduction to Atheism, Agnosticism, and Nonreligious Worldviews.". Psychology of Religion and Spirituality 10 (3): 203-206. doi:10.1037/re10000213.

Coleman III, Thomas J., and Ralph W. Hood Jr. 2015. "Reconsidering Everything: From Folk Categories to Existential Theory of Mind. [Peer Commentary on the Paper "From Weird Experiences to Revelatory Events" By A. Taves]." Religion and Society: Advances in Research 6(1): 18-22. doi:10.3167/arrs.2015.060102

Coleman III, Thomas J., Christopher F. Silver, and Ralph W. Hood Jr. 2016. "“....If the Universe Is Beautiful, We'Re Part of That Beauty." - A 'Neither Religious nor Spiritual' Biography as Horizontal Transcendence." In: Streib H., Hood, Jr. R. (eds) Semantics and Psychology of Spirituality. (Springer, Cham): pp. 355-372. doi:10.1007/978-3-31921245-6_22 
Cosmides, Leda, and John Tooby. 2000. "Consider the Source: The Evolution of Adaptations for Decoupling and Metarepresentation." In: Sperber D. (Ed) Metarepresentations: $A$ Multidisciplinary Perspective (New York: Oxford): pp. 53-115.

Davis, William E., Jacob Juhl, and Clay Routledge. 2011. "Death and Design: The Terror Management Function of Teleological Beliefs." Motivation and Emotion 35(1): 98-104. doi:10.1007/s11031-010-9193-6.

Dawkins, Richard. 2006. The God Delusion. London: Bantam Press.

De Cruz, Helen. 2016. "Divine Hiddenness and the Cognitive Science of Religion.” Chapter. In Hidden Divinity and Religious Belief: New Perspectives, edited by Adam Green and Eleonore Stump, 53-68. Cambridge: Cambridge University Press. doi:10.1017/CBO9781139939621.004.

Dechesne, Mark, Tom Pyszczynski, Jamie Arndt, Sean Ransom, Kennon M. Sheldon, Ad van Knippenberg, and Jacques Janssen. 2003. "Literal and Symbolic Immortality: The Effect of Evidence of Literal Immortality on Self-Esteem Striving in Response to Mortality Salience." Journal of Personality and Social Psychology 84(4): 722-737. doi:10.1037/0022-3514.84.4.722.

Farias, Miguel, Anna-Kaisa Newheiser, Guy Kahane, and Zoe de Toledo. 2013. "Scientific Faith: Belief in Science Increases in the Face of Stress and Existential Anxiety." Journal of Experimental Social Psychology 49(6): 1210-1213. doi:10.1016/j.jesp.2013.05.008.

Fazio, Russell H., and Michael A. Olson. 2003. "Implicit Measures in Social Cognition Research: Their Meaning and Use." Annual Review of Psychology 54(1): 297-327. doi:10.1146/annurev.psych.54.101601.145225.

Fazio, Russell H. 2007. "Attitudes as Object-Evaluation Associations of Varying Strength." Social Cognition 25(5): 603-637. doi:10.1521/soco.2007.25.5.603.

Fritsche, Immo, Eva Jonas, Peter Fischer, Nicolas Koranyi, Nicole Berger, and Beatrice Fleischmann. 2007. "Mortality Salience and the Desire for Offspring." Journal of Experimental Social Psychology 43(5): 753-762. doi:10.1016/j.jesp.2006.10.003.

Galen, Luke W. 2012. "Does Religious Belief Promote Prosociality? A Critical Examination." Psychological Bulletin 138(5): 876-906. doi:10.1037/a0028251.

Galen, Luke William, and James D. Kloet. 2011. "Mental Well-Being in the Religious and the Non-Religious: Evidence for a Curvilinear Relationship". Mental Health, Religion \& Culture 14(7): 673-689. doi:10.1080/13674676.2010.510829.

Galen, Luke. 2015. "Atheism, Wellbeing, And The Wager: Why Not Believing in God (With Others) Is Good for You." Science, Religion and Culture 2(3): 54-69.

doi:10.17582/journal.src/2015/2.3.54.69. 
Geertz, Armin W., and Guðmundur Ingi Markússon. 2010. "Religion is Natural, Atheism is Not: on Why Everybody is Both Right and Wrong." Religion 40(3): 152-165. doi:10.1016/j.religion.2009.11.003.

Geertz, Armin. 2013. Origins of Religion, Cognition and Culture. Durham: Acumen.

Gervais, Will M., Aiyana K. Willard, Ara Norenzayan, and Joseph Henrich. 2011. "The Cultural Transmission of Faith: Why Innate Intuitions are Necessary, But Insufficient, To Explain Religious Belief." Religion 41(3): 389-410. doi:10.1080/0048721x.2011.604510.

Gervais, Will M., Michiel van Elk, Dimitris Xygalatas, Ryan T. Mckay, Mark Aveyard, Emma E. Buchtel, and Ilan Dar-Nimrod et al. 2018. "Analytic Atheism: A Cross-Culturally Weak and Fickle Phenomenon?" Judgment and Decision Making 13(3): 268-274.

Gervais, Will M. 2015. "Override The Controversy: Analytic Thinking Predicts Endorsement of Evolution." Cognition 142: 312-321. doi:10.1016/j.cognition.2015.05.011.

Greenberg, Jeff, Linda Simon, Tom Pyszczynski, Sheldon Solomon, and Dan Chatel. 1992. "Terror Management and Tolerance: Does Mortality Salience Always Intensify Negative Reactions to Others Who Threaten One's Worldview?" Journal of Personality and Social Psychology 63(2): 212-220. doi:10.1037/0022-3514.63.2.212.

Greenberg, Jeff, Tom Pyszczynski, and Sheldon Solomon. 1986. "The Causes and Consequences of a Need for Self-Esteem: A Terror Management Theory". In Public Self and Private Self. R. Baumeister (Ed) (New York, NY: Springer-Verlag): pp. 189 - 212.

Greenwald, Anthony G., Debbie E. McGhee, and Jordan L. K. Schwartz. 1998. "Measuring Individual Differences in Implicit Cognition: The Implicit Association Test." Journal of Personality and Social Psychology 74(6): 1464-1480. doi:10.1037//0022-3514.74.6.1464.

Hanft, Ruth S. 1981. "Use of Social Science Data for Policy Analysis and Policy-Making." The Milbank Memorial Fund Quarterly. Health and Society 59(4): 596. doi:10.2307/3349743.

Heflick, Nathan A., and Jamie L. Goldenberg. 2011. "No Atheists in Foxholes: Arguments for (But Not Against) Afterlife Belief Buffers Mortality Salience Effects for Atheists." British Journal of Social Psychology 51(2): 385-392. doi:10.1111/j.20448309.2011.02058.x.

Heiphetz, Larisa, Jonathan D. Lane, Adam Waytz, and Liane L. Young. 2015. "How Children and Adults Represent God's Mind." Cognitive Science, 1-24. doi:10.1111/cogs.12232.

Henrich, Joseph. 2009. "The Evolution of Costly Displays, Cooperation and Religion." Evolution and Human Behavior 30(4): 244-260. doi:10.1016/j.evolhumbehav.2009.03.005.

Hood, Ralph W., and W. Paul Williamson. 2008. Them That Believe. Berkeley: University of California Press. 
"How Not to Criticize the (Evolutionary) Cognitive Science of Religion." 2014. [Review of the Book Evolution, Religion, \& Cognitive Science: Critical \& Constructive Essays, (Eds.), F. Watts \& L. Turner] Marginalia Review Of Books. doi:http://marginalia.lareviewofbooks.org/criticize-evolutionary-cognitive-sciencereligion/.

Jonas, Eva, and Peter Fischer. 2006. "Terror Management and Religion: Evidence That Intrinsic Religiousness Mitigates Worldview Defense Following Mortality Salience." Journal of Personality and Social Psychology 91(3): 553-567. doi:10.1037/0022-3514.91.3.553.

Jong, Jonathan, and Jamin Halberstadt. 2016. Death, Anxiety, and Religious Belief. London, UK: Bloomsbury Academic.

Jong, Jonathan. 2018. Beliefs are Object-Attribute Associations of Varying Strength." Contemporary Pragmatism 15(3): 284-301. doi:10.1163/18758185-01503002.

Jong, Jonathan. 2013. "Implicit Measures in the Experimental Psychology of Religion." In $A$ New Science of Religion, 65-78. New York: Routledge.

Krause, Neal, and R. David Hayward. 2014. "Religious Involvement and Death Anxiety." OMEGA - Journal of Death and Dying 69(1): 59-78. doi:10.2190/om.69.1.d.

Kurtz, P, and E Wilson. 1973. "Humanist Manifesto II." American Humanist Association. https://americanhumanist.org/what-is-humanism/manifesto2/. (accessed July 24, 2019)

Lanman, Jonathan A. 2008. "In Defence Of "Belief": A Cognitive Response to Behaviourism, Eliminativism, and Social Constructivism." Issues in Ethnology and Anthropology 3(3): 49-62. doi:10.21301/eap.v3i3.3.

Lanman, Jonathan. 2013. "Atheism and Cognitive Science." In The Oxford Handbook of Atheism. S. Bullivant and M. Ruse (eds) (Oxford: Oxford University Press): pp. 483-496.

Lavrič, Miran, and Sergej Flere. 2010. "Trait Anxiety and Measures of Religiosity in Four Cultural Settings." Mental Health, Religion \& Culture 13(7-8): 667-682. doi:10.1080/13674670701414961.

McCauley, Robert N. 2011. Why Religion is Natural and Science is Not. New York, N.Y: Oxford University Press.

McRae, Ken, and Michael Jones. 2013. "Semantic Memory." In The Oxford Handbook of Cognitive Psychology. D. Reisberg (Ed) (New York: Oxford University Press): pp. 206231.

Morgan, Jonathan. 2014. "Religion and Dual-Process Cognition: A Continuum of Styles or Distinct Types?" Religion, Brain \& Behavior 6(2): 112-129. doi:10.1080/2153599x.2014.966315. 
Norenzayan, Ara, Will M. Gervais, and Kali H. Trzesniewski. 2012. "Mentalizing Deficits Constrain Belief in a Personal God." Plos ONE 7(5): e36880. doi:10.1371/journal.pone.0036880.

Olson, Michael A., Russell H. Fazio, and H. Anna Han. 2009. "Conceptualizing Personal and Extrapersonal Associations." Social and Personality Psychology Compass 3(2): 152-170. doi:10.1111/j.1751-9004.2008.00164.x.

Payne, Brian Keith. 2001. "Prejudice and Perception: The Role of Automatic and Controlled Processes in Misperceiving a Weapon." Journal of Personality and Social Psychology 81(2): 181-192. doi:10.1037/0022-3514.81.2.181.

Pecher, Diane. 2013. "The Perceptual Representation of Mental Categories." In The Oxford Handbook of Cognitive Psychology. D. Reisberg (Ed) (New York: Oxford University Press): pp. 358-373.

Pennycook, Gordon, James Allan Cheyne, Nathaniel Barr, Derek J. Koehler, and Jonathan A. Fugelsang. 2013. "Cognitive Style and Religiosity: The Role of Conflict Detection." Memory \& Cognition 42(1): 1-10. doi:10.3758/s13421-013-0340-7.

Pennycook, Gordon, Robert M. Ross, Derek J. Koehler, and Jonathan A. Fugelsang. 2016. "Atheists and Agnostics are More Reflective than Religious Believers: Four Empirical Studies and a Meta-Analysis." PLOS ONE 11(4): e0153039. doi:10.1371/journal.pone.0153039.

Rosmarin, David H., Elizabeth J. Krumrei, and Gerhard Andersson. 2009. "Religion as a Predictor of Psychological Distress in Two Religious Communities." Cognitive Behaviour Therapy 38(1): 54-64. doi:10.1080/16506070802477222.

Rutjens, Bastiaan T., Frenk van Harreveld, Joop van der Pligt, Michiel van Elk, and Tom Pyszczynski. 2014. "A March to a Better World? Religiosity and the Existential Function of Belief in Social-Moral Progress." The International Journal for the Psychology of Religion 26(1): 1-18. doi:10.1080/10508619.2014.990345.

Schimel, Jeff, Linda Simon, Jeff Greenberg, Tom Pyszczynski, Sheldon Solomon, Jeannette Waxmonsky, and Jamie Arndt. 1999. "Stereotypes and Terror Management: Evidence That Mortality Salience Enhances Stereotypic Thinking and Preferences." Journal of Personality and Social Psychology 77(5): 905-926. doi:10.1037/0022-3514.77.5.905.

Silver, Christopher F., Thomas J. Coleman III, Ralph W. Hood Jr., and Jenny M. Holcombe. 2014. "The Six Types of Nonbelief: A Qualitative and Quantitative Study of Type and Narrative." Mental Health, Religion \& Culture 17(10): 990-1001. doi:10.1080/13674676.2014.987743. 
Speed, David, Thomas J. Coleman III, Luke W. Galen, and Karen Hwang. submitted. "In Doubt and Disbelief -How Mrdjenovich 2018 Misunderstands The (Non)Religion And Health Relationship". Journal of Religion and Health.

Speed, David, Thomas J. Coleman III, and Joseph Langston. 2018. "What Do You Mean, "What Does It All Mean?" Atheism, Nonreligion, And Life Meaning". SAGE Open 8 (1): 215824401775423. doi:10.1177/2158244017754238.

Stagaro, Michael N., Robert M. Ross, Gordon Pennycook, and David G. Rand. 2019. "CrossCultural Support for a Link between Analytic Thinking and Disbelief in God: Evidence from India and the United Kingdom". Judgment and Decision Making 14 (2): 179-186.

Swanson, Jane E., Laurie A. Rudman, and Anthony G. Greenwald. 2001. "Using the Implicit Association Test to Investigate Attitude-Behaviour Consistency for Stigmatised Behaviour". Cognition \& Emotion 15 (2): 207-230. doi:10.1080/02699930125706.

Taves, Ann. 2013. "Building Blocks of Sacralities". In Handbook of the Psychology of Religion and Spirituality, 2nd ed., R. Paloutzian and C. Park (eds) (New York: Guliford Press): pp. 138-161.

Taves, Ann. 2009. Religious Experience Reconsidered. Princeton, N.J: Princeton University Press.

Taves, Ann. 2015. "Reverse Engineering Complex Cultural Concepts: Identifying Building Blocks of "Religion"". Journal of Cognition and Culture 15 (1-2): 191-216. doi:10.1163/15685373-12342146.

Tracy, Jessica L., Joshua Hart, and Jason P. Martens. 2011. "Death and Science: The Existential Underpinnings of Belief in Intelligent Design and Discomfort with Evolution". Plos ONE 6 (3): e17349. doi:10.1371/journal.pone.0017349.

Uhlmann, E.L., T.A. Poehlman, and J.A. Bargh. 2008. "Implicit Theism". In Handbook of Motivation and Cognition Across Cultures. R. Sorrentino and S. Yamaguchi (eds) (Oxford, UK: Elsevier): pp. 71-94.

Vail, Kenneth E., Jamie Arndt, and Abdolhossein Abdollahi. 2012. "Exploring the Existential Function of Religion and Supernatural Agent Beliefs among Christians, Muslims, Atheists, and Agnostics". Personality and Social Psychology Bulletin 38 (10): 1288-1300. doi:10.1177/0146167212449361.

Vail, Kenneth E., Melissa Soenke, Brett Waggoner, and Ilianna Mavropoulou. 2019. "Natural, But Not Supernatural, Literal Immortality Affirmation Attenuates Mortality Salience Effects on Worldview Defense in Atheists". Personality and Social Psychology Bulletin, 014616721985505. doi:10.1177/0146167219855051. 
Vail, Kenneth E., Zachary K. Rothschild, Dave R. Weise, Sheldon Solomon, Tom Pyszczynski, and Jeff Greenberg. 2009. "A Terror Management Analysis of the Psychological Functions of Religion". Personality and Social Psychology Review 14 (1): 84-94. doi:10.1177/1088868309351165.

van den Bos, Kees, Josha Buurman, Veerle de Theije, Bertjan Doosje, Annemarie Loseman, Danique van Laarhoven, Tanja van Veldhuizen, and Jenny Veldman. 2012. "On Shielding From Death as an Important Yet Malleable Motive of Worldview Defense: Christian Versus Muslim Beliefs Modulating the Self-Threat of Mortality Salience". Social Cognition 30 (6): 778-802. doi:10.1521/soco.2012.30.6.778.

Van Leeuwen, Neil. 2014. "Religious Credence Is Not Factual Belief". Cognition 133 (3): 698715. doi:10.1016/j.cognition.2014.08.015.

van Mulukom, Valerie, Hugh Turpin, Benjamin Grant Purzycki, Roosa Haimila, Theiss Bendixen, Eva Kundtová Klocová, Dan Řezníček, Thomas J. Coleman III, Everton Maraldi, Kenan Sevinç, Uffe Schjoedt, Bastiaan Rutjens, and Miguel Farias. submitted. "What Do Non-Religious Non-Believers Believe In? Secular Worldviews around the World."

Von Eckardt, Barbara. 2012. "The Representational Theory of Mind". In The Cambridge Handbook of Cognitive Science. K. Frankish and W. Ramsey (eds) (Cambridge: Cambridge University Press): pp. 29-49.

Wiers, Reinout W., Jade van de Luitgaarden, Esther van den Wildenberg, and Fren T. Y. Smulders. 2005. "Challenging Implicit and Explicit Alcohol-Related Cognitions in Young Heavy Drinkers". Addiction 100 (6): 806-819. doi:10.1111/j.13600443.2005.01064.x. 